\title{
Covid 19: death certification in England and Wales
}

\author{
Thorough scrutiny of deaths remains essential during the covid-19 epidemic
}

\section{Tom Luce chair of 2001-03 fundamental review of death certification and investigation}

London, UK

Different views may be aired on the timeliness of the government's overall response to the predictable arrival in the UK of the coronavirus pandemic. Since then, however, there has been, at least in England and Wales, much prompt and comprehensive guidance from the relevant regulatory and service agencies. They include the general register office, the Ministry of Justice, the chief coroner for England and Wales, and NHS England.

Underpinning much of the guidance is the Coronavirus Act 2020, enacted quickly on 25 March 2020 with multiparty support. The act temporarily modifies some important death registration processes to reflect limitations imposed by lockdown and pressures on the medical profession. These include extending the period within which a doctor signing the death certificate should have "attended" the deceased from 14 to 28 days, allowing video consultation to meet that requirement, and, subject to the coroner's approval, ${ }^{1}$ accepting a non-attending doctor as signatory provided that they have access to the relevant clinical records. The act also simplifies the process for authorising cremations and allows funeral directors to act as informant to the registrar, with the family's agreement.

Guidance from the registrar general for England and Wales establishes that it is acceptable to put covid-19 on a death certificate as the main or underlying cause of death. ${ }^{2}$ It also states that covid-19 being a notifiable disease does not mean that every case must be reported to the coroner.

Many of these changes to death certification are reflected and elaborated in guidance from the chief coroner for England and Wales. ${ }^{3}$ The guidance includes the likely need to defer some coroners' investigations and inquests because of a lack of pathology services for timely postmortem examinations, and doctors' heavy clinical workload during the pandemic. The chief coroner also undertakes to justify the jurisdiction's response to the pandemic, including any lengthy delays to inquests, in his regular annual report to parliament.

\section{Notifying the coroner}

In normal times, the Ministry of Justice guidance on reporting of death to a coroner is underpinned by the definition of an "unnatural" death: "A death is typically considered to be unnatural if it has not resulted entirely from a naturally occurring disease process running its natural course, where nothing else is implicated."

This definition is important because it covers several likely scenarios during the pandemic, including deaths from covid-19 when late diagnosis (perhaps because of test shortages) or lack of treatment availability may have been a factor; when treatment is denied or withdrawn from vulnerable patients because of scarce resources; and deaths of health and care workers, particularly those associated with late or no testing or lack of protective equipment.

Interestingly, most of this important definition no longer features in the Ministry of Justice's recently updated guidance, though it still includes cases where the diagnosis was "delayed or erroneous, leading to either the death or acceleration of the death."

\section{Accountability}

Data from death certificates written by doctors independent of the state and conclusions from independent judicial coroners will be essential in quantifying the overall effect of the pandemic in England and Wales and for future pandemic planning. The data should also inform future judgments on the timeliness and effectiveness of responses from accountable central and local care organisations. Further inquiry may be needed to explore whether authorities properly discharged their emergency planning responsibilities under the Civil Contingencies Act 2004 and the NHS Act 2006.

It is therefore essential that all deaths should be carefully scrutinised and that doctors do not automatically assume that they need not report a death to a coroner simply because covid-19 is on the death certificate. Nor should they assume that the virus did not contribute to death simply because no test was done.

\section{Medical examiners}

Guidance from NHS England and NHS Improvement includes the sensible suggestion that medical examiners who had already been appointed as part of the new interim scheme should be used to complete death certificates when the treating doctor is 
not available. The legislation to give the interim scheme its full statutory basis may be delayed, but introduction of the full scheme should take place in April 2021 as planned. The full scheme is a long overdue and important improvement in death certification in England and Wales. ${ }^{5}$

I thank Andre Rebello and Fiona Wilcox for helpful comments.

Competing interests: I have read and understood BMJ policy on declaration of interests and have no interests to declare.

Provenance and peer review: Commissioned; not externally peer reviewed.

1 NHS England, NHS Improvement. Coronavirus act-excess deaths provisions: information and guidance for medical practitioners, 31 March 2020, https://improvement.nhs.uk
documents/6590/COVID-19-act-excess-death-provisions-info-and-guidance-31-march. pdf

2 Office for National Statistics, HM Passport Office. Guidance for doctors completing medical certificates of cause of death in England and Wales: for use during the emergency period only. 2020 https://assets.publishing.service.gov.uk/government/uploads/system/uploads/ attachment_data/file/877302/guidance-for-doctors-completing-medical-certificates-ofcause-of-death-covid-19.pdf

3 Chief Coroner's guidance on covid-19,26 Mar 2020. https://www.judiciary.uk/wp-content/ uploads/2020/03/Chief-Coroner-Guidance-No.-34-COVID-19_26_March_2020-.pdf

4 Notification of deaths regulations 2019 guidance. https://www.gov.uk/government/ publications/notification-of-deaths-regulations-2019-guidance

5 Luce T, Smith J. Death certification reform in England. BMJ 2018;361:k2668. 10.1136/bmj.k2668 29930196

Published by the BMJ Publishing Group Limited. For permission to use (where not already granted under a licence) please go to http://group.bmj.com/group/rights-licensing/ permissions 